\title{
Mechanical and Thermal Properties of Electrospun PMIA Nanofibers Reinforced PLA Composites
}

\author{
Bin HE *, Chao LIU, Zexing WANG \\ Institute of Textile and Fashion, Hunan Institute of Engineering, Xiangtan, Hunan, 411104, China \\ crossref http://dx.doi.org/10.5755/j01.ms.25.2.18759
}

Received 04 August 2017; accepted 05 April 2018

\begin{abstract}
The well-aligned electrospun Poly (mphenylene isophthalamide) (PMIA) nanofibers reinforced Polylactic acid (PLA) composites is fabricated via hot-pressing. Scanning electron microscopy (SEM), differential scanning calorimeter/thermal gravimetric analyser (DSC-TGA) and Dynamic Mechnical Analysis (DMA) are used to characterize morphologies of the broken sections and properties of composites. The results show that the tensile breaking strength and initial modulus have been enhanced much compared to that of pure PLA. The remarkable improvement emerges at the load 38 wt.\% of nanofibers with the tensile strength and initial modulus increase by ca. $235 \%$ and ca. $149 \%$, respectively. The hot-press process did not damage the nanofibers figuration and there are appear cracks link together with nanofibers by increasing the nanofiber contents. The initial degradation temperature of nanofibers reinforced composites are lower than that of pure PLA, but the final residual rate of composites increases with the increase of nanofibers mass fraction. Both the storage modulus and loss modulus of the composites increased with the addition of PMIA nanofibers. The addition of $38 \mathrm{wt} \%$ of nanofibers yields an increase of the storage modulus ca. $11 \%$ and the loss modulus ca. $13 \%$ at $40{ }^{\circ} \mathrm{C}$.

Keywords: electrospinning, nanofibers, composites, mechanical properties, thermal properties.
\end{abstract}

\section{INTRODUCTION}

The fiber-reinforced composites are very appropriate for high-performance components due to their excellent structural properties such as high strength-to-weight and stiffness-to-weight ratios, and the ability in providing both mechanical as well as functional performances $[1,2]$. At present, there have been increasing needs for light-weight materials in emerging mechanical and thermal properties, which can be used in aeronautics, vehicles, civil engineering and various structural applications [1,3]. In the development of light-weight materials, polymeric composites have received considerable attention $[4,5]$.

Nanofibers have a large specific surface area, high aspect ratio and other attractive multifunctional properties compared to conventional microfibers, they can provide more interaction between reinforcing fibers and polymer matrix and enables the applied load to be transferred on fibers-matrix interface, and lead to an improvement on the properties of the composites [6,7]. Electrospinning technique is a flexible and effective way to produce nanofibers with high speed, simple device and low cost [8-10].

In recent years, the use of electrospun nanofibers as reinforcements in polymeric composites has drawn people's attention [11-16]. Among them, Kim et al. [11] have estimated the reinforcing effects of electrospun polybenzimidazole (PBI) nanofibers in both epoxy and rubber matrices. They found that the PBI nanofibers toughened the brittle epoxy resin with higher fracture toughness and elastic moduli of $15 \mathrm{wt} \%$ nanofibers reinforced epoxy composites as compared to those of

\footnotetext{
* Corresponding author. Tel.: +8618973289695.

E-mail address: hb126_b@163.com (B. He)
}

composite counterparts of 17 wt.\% PBI fibrids. Uyar et al. [12] used electrospun polyvinylalcohol (PVA) to reinforce the Polymethylmethacrylate (PMMA) composites resins, and theirs results indicated that the mechanical properties of PMMA composites were improved, and the improvement was higher when aligned PVA nanofibers were used. The maximum values were $5.1 \mathrm{MPa}$ (flexural strength), $0.8 \mathrm{GPa}$ (elastic modulus), and $170 \mathrm{~kJ} \cdot \mathrm{m}^{-3}$ (toughness) in three-point bending test. Tang et al. [13] used the electrospun cellulose to reinforce PVA composites, they found that the nanofibers had improved the composites of tensile strength and Young's modulus by $50 \%$ and $600 \%$, respectively, with an optimal fiber content of $40 \mathrm{wt} . \%$. Chen et al. [14] have used the wellaligned electrospun polyimide (PI) nanofibers containing carbon nanotubes (CNTs) as reinforcement to heighten the tensile strength and toughness of PI films. Compared with pure PI film prepared by solution casting, the tensile breaking strength and elongation at break in the PI film reinforced with CNTs/PI nanofibers were strikingly increased by $138 \%$ and $104 \%$, respectively.

Poly (mphenylene isophthalamide)(PMIA) has especially prominent thermo-stability, high flame retardant and mechanical properties, etc [17]. Our group successfully prepared PMIA nanofibers with excellent morphology and mechanical properties via electrospinning [18], and following the previous work, well-aligned electrospun PMIA nanofibers were fabricated [19]. Polylactic acid (PLA) is a thermoplastic, bio-degradable and renewable polymer, which is industrially obtained respectively, through the polymerization of lactic acid or by the ringopening polymerization of lactide. The PLA is regarded as one of popular biopolymers which has gained enormous attention as an alternative to petrochemicalbased synthetic polymers in packaging and textile sectors 
and engineering at present. The production of PLA composites is realized using the following techniques mainly: (a) melt-compounding, (b) solvent-based, (c) pultrusion, (d) co-extrusion (fibers, films, sheets), (e) hot pressing (film stacking). Among them, techniques of (c), (d) and (e) are usually used to produce fiber reinforced PLA composites [20-22]. Okubo et al [23] have studied the process and properties of PLA nanocomposites, the microfibrillated cellulose (MFC) reinforced PLA composites were processed and they found that the addition of 1 and $2 \mathrm{wt} \%$ of MFC had a positive impact on the modulus as well as on composites' fracture energy with the maximum improvement of modulus by $31 \%$ and the fracture energy by almost $200 \%$, but the strength did not show any improvements. Haafiz et al [24] have prepared PLA composites filled with microcrystalline cellulose (MCC) through solution casting. They reported that the $\mathrm{T}_{50}$ decomposition temperature of the composites improved with addition of MCC which showed increase in thermal stability of the composites. The Young's modulus increased by about $30 \%$, while the tensile strength and elongation at break for composites decreased with addition of MCC. Niu et al [25] have used rosin modified cellulose nanofiber (R-CNF) to reinforce PLA matrix which was the coated with chitosan (CHT) to prepare a two-layer composite film. The Young's modulus of the composite film reached $962 \mathrm{MPa}$ with $8 \% \mathrm{R}-\mathrm{CNF}$, which was 1.498 times higher than that of neat PLA/CHT film.

In this paper, well-aligned electrospun PMIA nanofibers were fabricated, which have been used to reinforce the PLA matrix by layer-by-layer by using the hot-pressing. The effects of the PMIA nanofibers reinforced PLA composites on the tensile mechanical properties and morphologies of the broken sections and the thermal properties and the dynamic thermal mechanical properties were investigated in detail.

\section{EXEERIMENTAL DETAILS}

\subsection{Materials}

Commercial PMIA fibers (tensile breaking strength was ca. $4.5 \mathrm{cN} \cdot \mathrm{dtex}^{-1}$, and density $\left.1.37-1.38 \mathrm{~g} \cdot \mathrm{cm}^{-3}\right)$ were supplied by Yantai Spandex Co. Ltd. (China). PLA (PLLA, $\overline{M w} \approx 170000$ ) was provided by W. Wplastic Ningbo Co. Ltd. (China). Dimethylacetamide (DMAc) was purchased from J\&K Scientific Co. Ltd. Anhydrous lithium chloride (LiCl) was purchased from Shanghai Jufeng Chemical Scientific Co. Ltd. (China). Dichloromethane was provided by Sinopharm Chemical Reagent Co., Ltd. (China). All the chemicals were of analytical reagent grade.

\subsection{Preparation of electrospun nanofibers}

Firstly, the spinning solution was prepared with the PMIA and $\mathrm{LiCl}$ in the solution were 12 wt.\% and 6 wt.\%, respectively. Then the well-aligned electrospun PMIA namofibers were fabricated via electrospinning on the Nanofiber Electrospinning Unit (KATO TECH Co. Ltd., Japan). Spinning parameters were as follows: inner diameter of spinneret $0.45 \mathrm{~mm}$, voltage $23 \mathrm{kV}$, collecting spinning distance $11 \mathrm{~cm}$, solution flow rate $0.26 \mathrm{ml} \cdot \mathrm{h}^{-1}$, spinneret scan speed $14 \mathrm{~cm} \cdot \mathrm{min}^{-1}$, collector rotating speed
$6 \mathrm{~m} \cdot \mathrm{min}^{-1}$. The detailed steps were described in our previous work [19].

\subsection{Preparation of hot-pressed nanofibers reinforced composites}

Firstly, the PLA was added into dichloromethane and stirred untill it was dissolved completely with the mass fractions of PLA is about $3 \sim 4 \%$, and followed 2 layers of the well-aligned PMIA nanofibers $(50 \mathrm{~mm} \times 40 \mathrm{~mm})$ were laminated into the solution layer-by-layer. Then the solvent evaporated at room temperature and gained the prepregs. Then the prepregs were hot-pressed at the parameters of pressure as $1000 \mathrm{~Pa}$, temperature as $180{ }^{\circ} \mathrm{C}$, time as $30 \mathrm{~min}$, and trimmed their sides carefully after cooling under the room temperature, as shown in Fig. 1. The composites obtained finally with the mass fractions of nanofibers in composites were controlled range from $0 \%$ to $50 \%$.

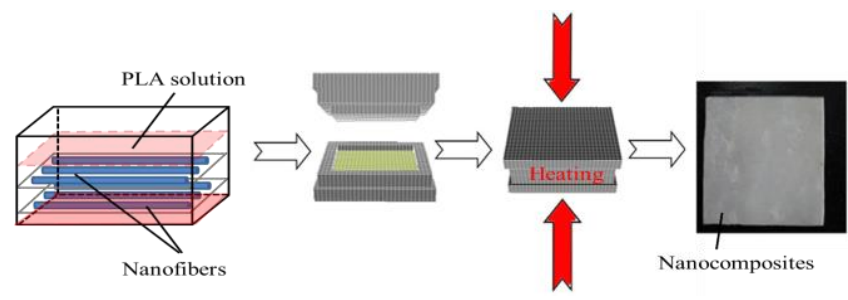

Fig. 1. The schematic diagram of composites forming

\subsection{Measurements}

The mechanical properties of the composites were tested by Instron 5967 mechanical testing machine with gauge length $20 \mathrm{~mm}$, crosshead speed $20 \mathrm{~mm} \cdot \mathrm{min}^{-1}$. The tensile test progressed along the axial (parallel to the aligned fibers) directions, and the sample was cut into dumbbells showed in Fig. 2. The tensile strength at breakage was calculated by the mean of 5 samples. All of the samples were conditioned in a laboratory environment $\left(20 \pm 1{ }^{\circ} \mathrm{C}\right.$ and $65 \pm 3 \%$ ) for $24 \mathrm{~h}$ before testing.

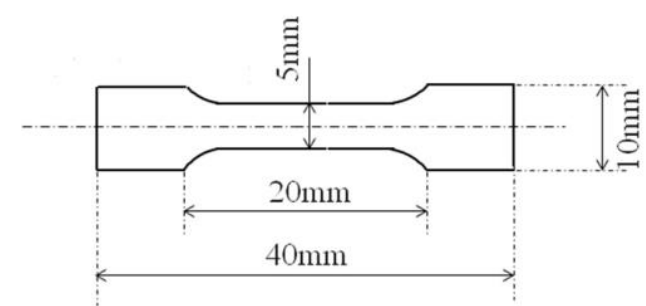

Fig. 2. The sample diagram of tensile test

The morphologies of the electrospun PMIA nanofibers and the morphologies of the broken sections of the composites after the tensile test were observed by scanning electron microscopy (SEM) (Hitachi S-4800, Japan). The mean diameter of fibers was measured by image analyzing system (Image-Pro Plus 5.0), and 100 measurements were taken, then the average value was calculated.

Thermal properties of the composites were evaluated by using an SDT Q600 simultaneous differential scanning calorimeter/thermal gravimetric analyser (DSC-TGA) instrument (TA Instruments, USA). The sample was ramped at $10^{\circ} \mathrm{C} \cdot \mathrm{min}^{-1}$ from room temperature to $600{ }^{\circ} \mathrm{C}$ under a nitrogen atmosphere. 
The Dynamic Mechnical Analysis (DMA) of the composites was measured by using the DMA Q800 instrument (TA Instruments, USA). The sample was ramped at $3{ }^{\circ} \mathrm{C} \cdot \mathrm{min}^{-1}$ from $30{ }^{\circ} \mathrm{C}$ to $240{ }^{\circ} \mathrm{C}$ with the test frequency of $1 \mathrm{~Hz}$ in stretch film test patter. The sample size is $36 \mathrm{~mm} \times 6 \mathrm{~mm}$.

\section{RESULTS AND DISCUSSION}

\subsection{Nanofibers morphology}

Fig. 3 and Fig. 4 show SEM image and the diameter distribution of the PMIA nanofibers. It is clearly that the nanofibers were uniform and well-aligned along the fiber axis. The average diameter of nanofibers is about $298.52 \pm 53.58 \mathrm{~nm}$.

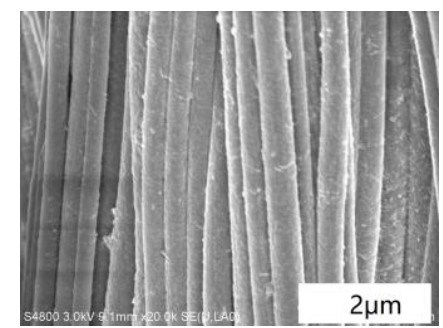

Fig. 3. SEM image of the PMIA nanofibers

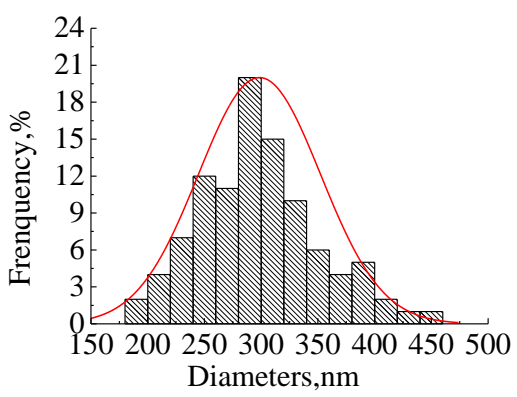

Fig. 4. Diameter distribution of the PMIA nanofibers

\subsection{Mechanical properties}

Fig. 5 and Table 1 show the mechanical properties of composites at different eletrospun PIA nanofiber contents. The thickness of the composites with different nanofiber contents of $0,10,23,30,38$ and 49 wt.\% were $0.293 \pm 0.016,0.206 \pm 0.013,0.235 \pm 0.015,0.268 \pm 0.014$ $0.296 \pm 0.013$ and $0.315 \pm 0.016 \mathrm{~mm}$, respectively. The results indicated that the tensile breaking strength and initial modulus had been enhanced much compared to that of pure PLA. The remarkable improvement emerges at the load 38 wt.\% of nanofibers with the tensile breaking strength and initial modulus increased by ca. $235 \%$ and ca. $149 \%$, respectively. There is a higher rate of increase of the tensile strength and the initial modulus of PMIA/PLA composites comparing with some other reports [23-25] about PLA composites. The mechanical properties of fiberreinforced composites. The mechanical properties of fiberreinforced composites largely depend on stress transfer of fiber and matrix; the fibers undertake the main load during the tensile process. So the mechanical properties of composites increased with the increase of fiber content in a certain extent. However, when the fiber contents exceed a certain amount, the adhesion between the fiber and the matrix becomes worse due to the decrease of the mass fraction of the matrix, and even can arise the matrix poor area, which can lead to the emergence of matrix discontinuity. The stress transfer between the matrix and the fiber is disjointed, and the mechanical properties of the composites decrease. That is may be the reason to explain the tensile breaking strength and initial modulus of the composites decreased at the load $49 \mathrm{wt} \%$ of nanofibers.

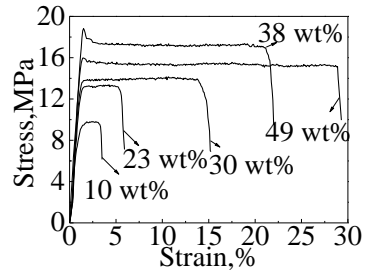

a

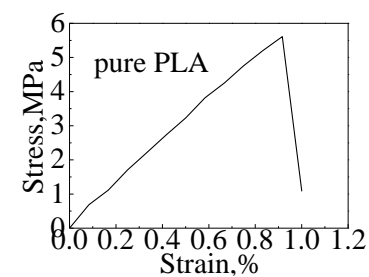

b
Fig. 5. Mechanical properties of composites: a-mass fractions of nanofibers range from $10 \%$ to $50 \%$; b-pure PLA (0 wt.\%)

\subsection{Morphologies of the broken sections}

Fig. 6 shows SEM images of the broken sections of the composites after the tensile test, the inserted image is the magnified parts. The nanofibers revealed excellent morphologies, which demonstrated that the hot-press process did not damage the nanofibers figuration. There is only a single neat fracture when tensile fracture occurs at the load 0,10, 23 wt.\% of nanofibers, and there are appears cracks link together with nanofibers by increasing the nanofiber contents of 33, 38, 49 wt.\%. For the reason is that the bonding interface between nanofibers and matrix is increased by increasing the nanofiber contents, the nanofibers are not pulled or broken during the tensile process, which hinders the fracture formation from the crack, that is beneficial to the enhancement of tensile mechanical properties. For the load 49 wt. $\%$ of nanofibers, the number of slipped nanofibers increased because of the emergence of matrix poor area, and the matrix appears the fault phenomenon after the stretching, which further explains the reason for the decline on mechanical properties at the load $49 \mathrm{wt} . \%$ of nanofibers.

Table 1. Mechanical properties of the composites

\begin{tabular}{|l|c|c|c|c|c|c|}
\hline $\begin{array}{l}\text { Nanofiber } \\
\text { contents, wt.\% }\end{array}$ & 0 & 10 & 23 & 30 & 38 & 49 \\
\hline $\begin{array}{l}\text { Tensile breaking } \\
\text { strength, MPa }\end{array}$ & $5.61 \pm 0.52$ & $9.82 \pm 1.15$ & $13.32 \pm 1.41$ & $14.09 \pm 1.69$ & $18.77 \pm 1.73$ & $15.91 \pm 1.97$ \\
\hline $\begin{array}{l}\text { Initial modulus, } \\
\mathrm{MPa}\end{array}$ & $610.03 \pm 63.75$ & $720.60 \pm 86.52$ & $1306.77 \pm 137.57$ & $1426.27 \pm 156.83$ & $1517.25 \pm 148.99$ & $1372.03 \pm 178376$ \\
\hline
\end{tabular}



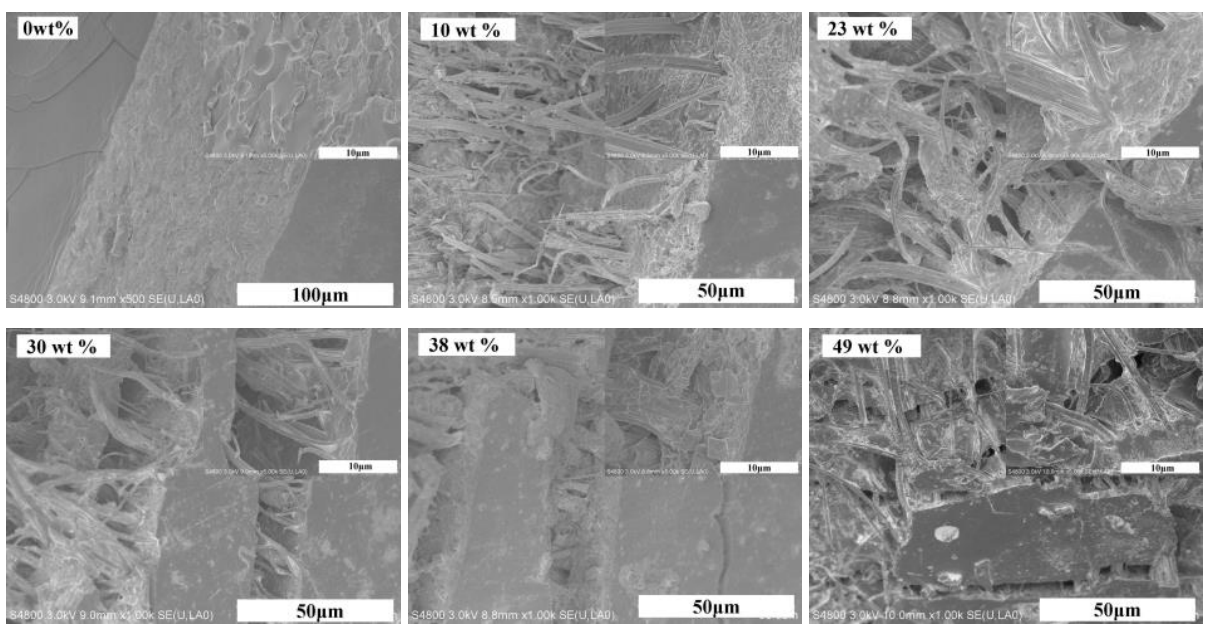

Fig. 6. SEM images of the broken sections of the composites after the tensile test

\subsection{Thermal analysis}

Fig. 7 shows DSC-TGA curves of the composites at different nanofiber contents. On DSC curve of pure PLA ( 0 wt. \%), it can be seen that there are three endothermic peaks near $90{ }^{\circ} \mathrm{C}$ and $150{ }^{\circ} \mathrm{C}$ and $340{ }^{\circ} \mathrm{C}$, which are caused by the volatilization of adsorbed water in PLA and by the melting of PLA and by the decomposition of PLA, respectively. There is significant mass loss take place from $250{ }^{\circ} \mathrm{C}$ to $400{ }^{\circ} \mathrm{C}$ correspond to the TGA curve. For the nanofibers reinforced composites, there are two peaks endothermic peaks near $90{ }^{\circ} \mathrm{C}$ and $150{ }^{\circ} \mathrm{C}$ as the same of pure PLA. The strong endothermic peak near $280 \sim 300{ }^{\circ} \mathrm{C}$ caused by PLA decomposition in addition to the release of crystal waters in PMIA nanofibers. The decomposition temperature of the composites is lower than that of pure PLA for the reason is that the $\mathrm{LiCl}$ attached to the PMIA nanofibers has high water absorbing ability, and water molecules can promote the fracture of PLA ester bond, which brings the accelerated thermal degradation of PLA. The initial degradation temperature of nanofibers reinforced composites are also lower than that of pure PLA showed on TGA curves. The endothermic peak near $370{ }^{\circ} \mathrm{C}$ may be caused by thermal decomposition of PMIA. The TGA curves show that the final residual rate of composites increases with the increase of nanofibers mass fraction. This is because that the PLA has been degraded at the temperature lower than $400{ }^{\circ} \mathrm{C}$ and only the thermal degradation of PMIA occurs at a temperature range of $400 \sim 600{ }^{\circ} \mathrm{C}$.

\subsection{Dynamical mechanical analysis (DMA)}

The dynamic thermal mechanical properties of composites are depicted in Fig. 8. The results indicated that both the storage modulus and the loss modulus of the composites increased with the addition of PMIA nanofibers. The addition of $38 \mathrm{wt} \%$ of nanofibers yielded an increase of the storage modulus ca. $11 \%$ and the loss modulus ca. $13 \%$ at $40{ }^{\circ} \mathrm{C}$. This behavior can be explained in terms of interfacial interactions between the PMIA nanofibers and PLA matrix [26].

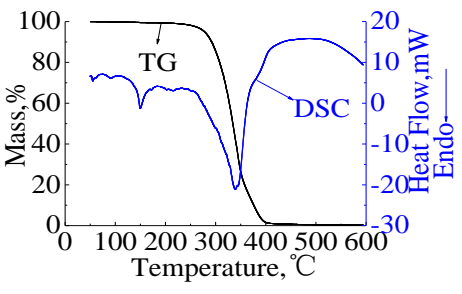

a

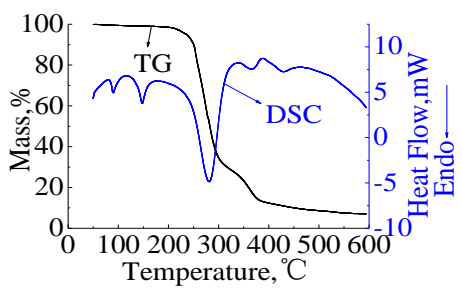

d

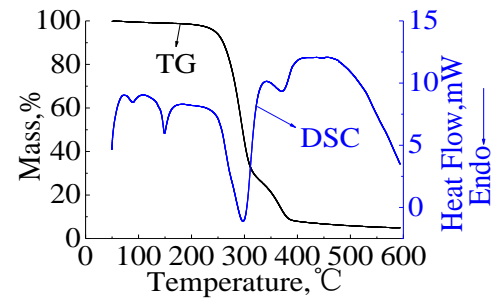

b

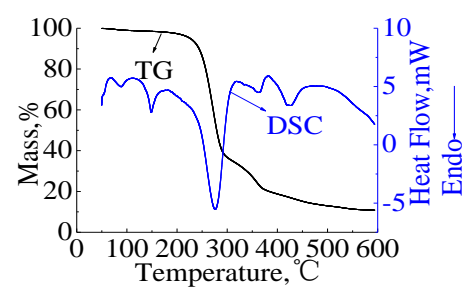

e

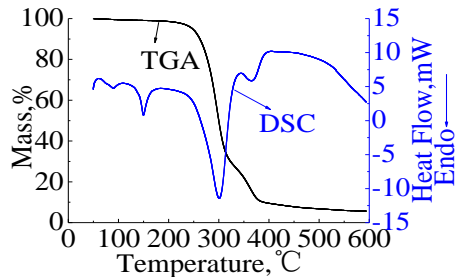

$\mathrm{c}$

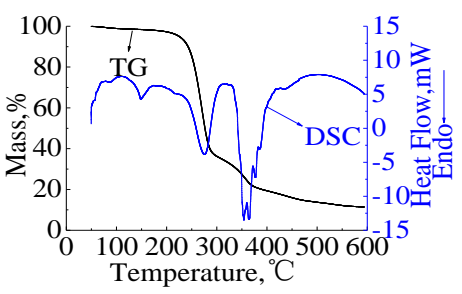

f

Fig. 7. TGA-DSC curves of the composites at different nanofiber contents: a-pure PLA; b-10wt.\%; c-23 wt.\%; d-30wt.\%; e-38 wt. \%; f-49 wt.\% 
Both the storage modulus and loss modulus of pure PLA are reduced to zero due to the PLA macromolecule chain are in a state of completely free movement when over $150{ }^{\circ} \mathrm{C}$, while there are the existence of storage modulus and loss modulus in composites because of the PMIA nanofibers are withstand stress in the same condition.

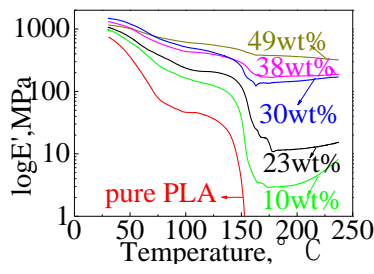

a

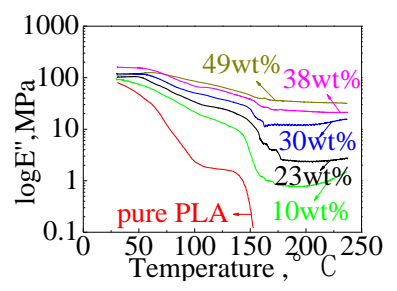

b
Fig. 8. The dynamic thermal mechanical properties of composites $\mathrm{a}$-storage modulus (E'); b-loss modulus (E")

\section{CONCLUSIONS}

Well-aligned PMIA nanofibers with the average diameter about $298.52 \pm 53.58 \mathrm{~nm}$ were fabricated via electrospinning, which had been used to reinforce the PLA matrix by layer-by-layer via hot-pressing. The results showed that the tensile breaking strength and initial modulus had been enhanced much compared to that of pure PLA. The remarkable improvement occurs at the load 38 wt.\% of nanofibers with the tensile strength and initial modulus increased by ca. $235 \%$ and ca. $149 \%$, respectively. The broken sections of the composites after the tensile test showed that the hot-press process did not damage the nanofibers figuration. There is only a single neat fracture when tensile fracture emerges at the load 0 , 10,23 wt. $\%$ of nanofibers, and there are appear cracks link together with nanofibers by increasing the nanofiber contents of $30,38,49 \mathrm{wt} . \%$. The initial degradation temperature of nanofibers reinforced composites are lower than that of pure PLA, but the final residual rate of composites increases with the increase of nanofibers mass fraction. Both the storage modulus and loss modulus of the composites increased with the addition of PMIA nanofibers. The addition of 38 wt. $\%$ of nanofibers yielded an increase of the storage modulus ca. $11 \%$ and the loss modulus ca. $13 \%$ at $40{ }^{\circ} \mathrm{C}$.

\section{Acknowledgments}

This work was supported by the Doctoral Scientific Research Foundation of Hunan Institute of Engineering [14082, 14093].

\section{REFERENCES}

1. Mohammadzadehmoghadam, S., Dong, Y., Davies, I.J. Recent Progress in Electrospun Nanofibers: Reinforcement Effect and Mechanical Performance Journal of Polymer Science Part B Polymer Physics 53 (17) 2015: pp. $1171-1212$. https://doi.org/10.1002/polb.23762

2. Asmatulu, E., Twomey, J., Overcash, M. Recycling of Fiber-Reinforced Composites and Direct Structural
Composite Recycling Concept Journal of Composite Materials 48 (5) 2014: pp. 593-608.

https://doi.org/10.1177/0021998313476325

3. Song, W.L., Veca, L.M., Anderson, A., Cao, M.S., Cao, L., Sun, Y.P. Light-weight Nanocomposite Materials with Enhanced Thermal Transport Properties Nanotechnology Reviews 1 (4) 2012: pp. 363-375. https://doi.org/10.1515/ntrev-2012-0023

4. Paul, D.R., Robeson, L.M. Polymer Nanotechnology: Nanocomposites Polymer 49 (15) 2008: pp. 3187-3204. https://doi.org/10.1016/j.polymer.2008.04.017

5. Kim, H., Abdala, A.A., Macosko, C.W. Graphene/Polymer NNanocomposites Macromolecules 43 (16) 2010: pp. $6515-6530$. https://doi.org/10.1021/ma100572e

6. Schaefer, D.W., Justice, R.S. How Nano are Nanocomposites? Macromolecules 40 (24) 2007: pp. $8501-8517$. https://doi.org/10.1021/ma070356w

7. Lin, S., Cai, Q., Ji, J., Sui, G., Yu, Y., Yang, X., Ma, Q., Wei, Y., Deng, X. Electrospun Nanofiber Reinforced and Toughened Composites Through in Situ Nano-interface Formation Composites Science and Technology 68 (15-16) 2008: pp. 3322-3329.

https://doi.org/10.1016/j.compscitech.2008.08.033

8. Huang, Z.M., Zhang, Y.Z., Kotaki, M., Ramakrishna, S. A Review on Polymer Nanofibers by Electrospinning and Their Applications in Nanocomposites Composites Science and Technology 63 (15) 2003: pp. 2223-2253. https://doi.org/10.1016/S0266-3538(03)00178-7

9. Angammana, C.J, Jayaram, S.H. Fundamentals of Electrospinning and Processing Technologies Particulate Science and Technology 34 (1) 2016: pp. $72-82$. https://doi.org/10.1080/02726351.2015.1043678

10. Mirjalili, M., Zohoori, S. Review for Application of Electrospinning and Electrospun Nanofibers Technology in Textile Industry Journal of Nanostructure in Chemistry 6 (3) 2016: pp. $1-7$. https://doi.org/10.1007/s40097-016-0189-y

11. Kim, J.S., Reneker, D.H. Mechanical Properties of Composites using Ultrafine Electrospun Fibers Polymer Composites 20 (1) 2010: pp. 124-131. https://doi.org/10.1002/pc.10340

12. Uyar, T., Çökeliler, D., Doğan, M., Koçum, I.C., Karatay, O., Denkbaş, E.B. Electrospun Nanofiber Reinforcement of Dental Composites with Electromagnetic Alignment Approach Materials Science and Engineering C 62 2016: pp. 762. https://doi.org/10.1016/j.msec.2016.02.001

13. Tang, C., Liu, H. Cellulose Nanofiber Reinforced Poly(vinyl alcohol) Composite Film with High Visible Light Transmittance Composites Part A: Applied Science \& Manufacturing 39 (10) 2008: pp. 1638-1643. https://doi.org/10.1016/j.compositesa.2008.07.005

14. Chen, D., Wang, R., Tjiu, W.W., Liu, T. High Performance Polyimide Composite Films Prepared by Homogeneity Reinforcement of Electrospun Nanofibers Composites Science and Technology 71 (13) 2011: pp. $1556-1562$. https://doi.org/10.1016/j.compscitech.2011.06.013

15. Chen, J., Li, X., Cui, W., Zou, J., Zou, B. Fibrous Composites with Anisotropic Distribution of Mechanical Properties after Layer-by-Layer Deposition of Aligned 
Electrospun fibers Advanced Engineering Materials 2010: pp. $529-538$.

https://doi.org/10.1002/adem.200980079

16. Li, B., Pan, S., Yuan, H., Zhang, Y. Optical and Mechanical Anisotropies of Aligned Electrospun Nanofibers Reinforced Transparent PMMA Nanocomposites Composites Part A 90 2016: pp. 380-389. https://doi.org/10.1016/j.compositesa.2016.07.024

17. Machalaba, N.N., Perepelkin, K.E. Heterocyclic Aramide fibers - Production Principles, Properties and Application Journal of Industrial Textiles 3 2002: pp. 189-204. https://doi.org/10.1101/152808302026484

18. He, B., Li, J., Pan, Z. Morphology and Mechanical Properties of MWNT/PMIA Nanofibers by Electrospinning Textile Research Journal 82 (13) 2012: pp. 1390-1395. https://doi.org/ 10.1177/0040517512441990

19. He, B., Tian, L., Li, J., Pan, Z. Effect of Hot-Stretching on Morphology and Mechanical Properties of Electrospun PMIA Nanofibers Fibers and Polymers 14 (3) 2013: pp. $405-408$. https://doi.org/10.1007/s12221-013-0405-Z

20. Baiardo, M., Frisoni, G., Scandola, M., Rimelen, M., Lip, D., Ruffieux, K., Wintermantel, E. Thermal and Mechanical Properties of Plasticized Poly(L-lactic acid) Journal of Applied Polymer Science 90 (7) 2003: pp. $1731-1738$. https://doi.org/10.1002/app.12549

21. Auras, R., Harte, B., Selke, S. An Overview of Polylactides as Packaging Materials Macromolecular Bioscience 4 (9) 2004: pp. $835-864$. https://doi.org/10.1002/mabi.200400043

22. Murariu, M., Dubois, P. PLA composites: From Production to Properties Advanced Drug Delivery Reviews 107 2016: pp. $17-46$. https://doi.org/10.1016/j.addr.2016.04.003

23. Okubo, K., Fujii, T., Thostenson, T. Multi-scale Hybrid Biocomposite: Processing and Mechanical Characterization of Bamboo Fiber Reinforced PLA with Microfibrillated Cellulose Composites Part A 40 (4) 2009: pp. 469-475. https://doi.org/10.1016/j.compositesa.2009.01.012

24. Haafiz, M.K., Hassan, A., Zakaria, Z., Inuwa, I.M. Properties of Polylactic Acid Composites Reinforced with Oil Palm Biomass Microcrystalline Cellulose Carbohydrate Polymers 98 (1) 2013: pp. 139-145. https://doi.org/10.1016/j.carbpol.2013.05.069

25. Niu, X., Liu, Y., Song, Y., Han, J., Pan, H. Rosin Modified Cellulose Nanofiber as a Reinforcing and Co-Antimicrobial Agents in Polylactic Acid /Chitosan Composite Film For Food Packaging Carbohydrate Polymers 183 2018: pp. $102-109$. https://doi.org/10.1016/j.carbpol.2017.11.079

26. Gabr, M.H., Phong, N.T., Okubo, K., Uzawa, K., Kimpara, I., Fujii, T. Thermal and Mechanical Properties of Electrospun Nano-celullose Reinforced Epoxy Nanocomposites Polymer Testing 37 (8) 2014: pp. $51-58$. https://doi.org/10.1016/j.polymertesting.2014.04.010 